\title{
Legal Control on Social Control of Sex Offenders in the Community: A European Comparative and Human Rights Perspective
}

\author{
Michiel van der Wolf (Issue Editor)*
}

\begin{abstract}
This paper provides first of all the introduction to this special issue on 'Legal constraints on the indeterminate control of "dangerous" sex offenders in the community: A European comparative and human rights perspective'. The issue is the outcome of a study that aims at finding the way legal control can not only be an instrument but also be a controller of social control. It is explained what social control is and how the concept of moral panic plays a part in the fact that sex offenders seem to be the folk devils of our time and subsequently pre-eminently the target group of social control at its strongest. Further elaboration of the methodology reveals why focussing on post-sentence (indeterminate) supervision is relevant, as there are hardly any legal constraints in place in comparison with measures of preventive detention. Therefore, a comparative approach within Europe is taken on the basis of country reports from England and Wales, France, Germany, The Netherlands and Spain. In the second part of the paper, the comparative analysis is presented. Similar shifts in attitudes towards sex offenders have led to legislation concerning frameworks of supervision in all countries but in different ways. Legal constraints on these frameworks are searched for in legal (sentencing) theory, the principles of proportionality and least intrusive means, and human rights, mainly as provided in the European Convention on Human Rights to which all the studied countries are subject. Finally, it is discussed what legal constraints on the control of sex offenders in the community are (to be) in place in European jurisdictions, based on the analysis of commonalities and differences found in the comparison.
\end{abstract}

Keywords: social control, folk devils, moral panic, dangerousness, sex offenders

\footnotetext{
Ph.D., LL.M, M.Sc., Reader in Criminal Law (Theory) and Forensic Psychiatry at the Erasmus School of Law; Member of the Editorial Board of the Erasmus Law Review. This paper provides the concluding piece of a comparative research project headed by the author, funded through a Veni-grant of the Netherlands Organisation for Scientific Research (NWO). The country contributions that are referred to are the other contributions to this special issue, concluded at the end of spring in 2016. The project has been jointly presented on a symposium as part of the Conference of the International Academy for Law and Mental Health in Vienna, 17 July 2015. Thank you to the contributing authors for your cooperation, expertise and patience.
}

\section{Introduction: Background, Relevance and Approach}

\subsection{Law as an Instrument and Controller of Social Control}

In 1985, then already an influential author in sociology and criminology, Stanley Cohen published his book 'Visions of social control'. In regard to the term social control, he discerns that it appears in the literature as a neutral term to cover all social processes to induce conformity ranging from infant socialization through to public execution, as well as a negative term to cover both the obvious and putative hidden element in all state-sponsored social policy, whether called health, education or welfare. For his own purpose of showing shifts in programmed social control, he then narrows the term to

the organized ways in which society responds to behavior and people it regards as deviant, problematic, worrying, threatening, troublesome or undesirable in some way or another. This response appears under many terms: punishment, deterrence, treatment, prevention, segregation, justice, rehabilitation, reform or social defence. ${ }^{1}$

Many, if not all, of these responses are established through law, making law the most prominent instrument of social control as he defines it.

Regarding the current developments in criminal law, Cohen's visions seem to be truly visionary. Among the shifts he observed in 1985 is a generally enlarging and more intrusive system, 'subjecting more and newer groups of deviants to the power of the state and increasing the intensity of control directed at former deviants'. ${ }^{2}$ This development is echoed in the chain of writings since then on the criminal justice implications of the identified 'risk society', ${ }^{3}$ 'culture of fear' ${ }^{4}$ and the sup-

\footnotetext{
S. Cohen, Visions of Social Control (1985), at 1.

Ibid., 38.

E.g. U. Beck, Risk Society. Towards a New Modernity (1992).

E.g. F. Furedi, Culture of Fear: Risk Taking and the Morality of Low Expectation (1997).
} 
plementary 'risk paradigm'. 5 The international literature on how fear and risk are 'managed' through criminal justice emphasizes similarly that the subsequent array of legislative and policy-making initiatives in the Western world is targeted at certain groups of criminal offenders. These groups seem to be singled out for legal control as 'dangerous' because of the way in which they are perceived as 'different' to the social norm. And as fearbased policies tend to view 'justice' as synonymous with discipline, these groups are being viewed as 'beyond principles of due process' ${ }^{6}$

This notion is itself deviant from a general view in legal theory that especially criminal law is not only an instrument of the exertion of State power, for example, to ensure safety for the general public, but also a balancing mechanism to keep that exertion in check and protect (the rights of) the individual. As law was already identified as the instrument of social control par excellence, the question that arises and that is addressed in this research is what remains of law as a controller of that control in the current advanced stage of Cohen's enlarging system.

\subsection{Focus on Sex Offenders as the Folk Devils of} Our Current Moral Panic

Among the usual suspects that appear in literature as the mentioned targeted groups are terrorists, immigrants, mentally disordered and sex offenders. Particularly in regard to that last group, the term social control is currently fashionable again. ${ }^{7}$ And this observation applies similarly to the association between sex offenders and two other phrasings, not introduced but coined in another classic work by Stanley Cohen from 1972, 'Folk Devils and Moral panics'. While Cohen used these terms for describing the social reaction to the groups of Mods and Rockers, two at the time conflicting British youth subcultures, they are now being used, for example, to understand the dynamics surrounding re-entry of sex offenders in the community after release from custody. ${ }^{8}$

Sex offenders seem to have become today's 'folk devils', a term used by Cohen to describe the mechanism of why a certain group of people is portrayed in folklore or media as deviant and to blame for crimes and other social problems. ${ }^{9}$ Jenkins identified in the United States a number of persisting allegations regarding the threat posed by sex offenders that were accepted as facts by the population even though they contained only 'fragments of truth':

5. Meaning the avoidance of risk in many areas of personal and social life, for example, presented in a series named 'beyond the risk paradigm' on different aspects of society. E.g. C. Trotter, G. Mclvor \& F. McNeill (eds.), Beyond the Risk Paradigm in Criminal Justice (2016).

6. D. Denney, 'Fear, Human Rights and New Labour Policy Post-9/11', 42 Social Policy and Administration 560 (2008).

7. E.g. D.R. Laws, Social Control of Sex Offenders (2016); D. Rickard, Sex Offenders, Stigma, and Social Control (2016).

8. M. Boone and H. Van de Bunt, 'Dynamics between Denial and Moral Panic: The Identification of Convicted Sex Offenders in the Community', 63 Probation Journal 23 (2016).

9. S. Cohen, Folk Devils and Moral Panics: The Creation of the Mods and Rockers (1972).
- Children face a terrible danger of being sexually abused.

- Sexual abuse is a problem of wide dimensions.

- Sex offenders are compulsive and offend frequently.

- Sex offenders cannot be cured or rehabilitated.

- Sexually deviant behaviour can escalate to murder.

- Sex with adults causes lasting harm to victims.

- Sexual abuse can produce the so-called cycle of abuse such that abused children will later perpetrate the same act against new victims. ${ }^{10}$

These allegations show that the shift from the possible threat of sex offenders to moral outrage is usually made through emphasizing the subgroup convicted for a sex offence against children, often unjustly equated with the group of paedophiles. ${ }^{11}$ Explaining the shift in status from threat to moral outrage is also mainly attempted in regard to this subgroup. In 'The moral crusade against paedophilia', sociologist Frank Furedi argues that 'the paedophile personifies evil in 21st-century society; the child predator possesses the stand-alone status of the embodiment of malevolence'. ${ }^{12}$ He describes how what first emerged as a moral panic in the 1980s mutated into a coherent and enduring ideology of evil. The overreaction, also in the media, leads to the idea of an omnipresent threat of this behaviour, which is in fact quite rare. The 'normalisation' of an existential threat haunting childhood and 'the natural order of things' leads to suspicion concerning intergenerational relations and even no-touch and no-picture rules in nurseries and schools. It also creates zealous moral entrepreneurs or crusaders as it provides opportunities for moral positioning against the one evil that all of us can agree on - the strategic position of a last-standing uncontested moral code. Furedi believes this to be connected to the sacralisation of the child as moral opposite of the evil paedophile. In a world of existential disorientation, the child serves as the main focus for both emotional and moral investment. ${ }^{13}$ Some believe that a sublimated form of guilt accounts for this dynamic. For example, David Garland, another sociologist who has worked on criminal justice, wrote that 'the intensity of current fear and loathing of child abusers seems to be connected to unconscious guilt about negligent parenting and widespread ambivalence about the sexualisation of modern culture'. ${ }^{14}$ Since using children as a moral shield is now widely practiced by policy makers and fear entrepreneurs, this is too often taken literally in the front row of a mob in front of a courthouse or an identified paedophile home. Psychiatrist and publicist Theodore Dalrymple suggests that exposing children to such scenes is itself abusive, claiming that most of the adults taking their children to such

10. P. Jenkins, Moral Panic: Changing Concepts of the Child Molester in Modern America (1998), at 1-4.

11. For a more detailed description of the dynamics of moral panic with regard to sex offenders, see Laws, above n. 7 .

12. F. Furedi, 'The Moral Crusade against Paedophilia', in V.E. Cree, G. Clapton \& M. Smith, Revisiting Moral Panics (2016).

13. F. Furedi, Paranoid Parenting (2008).

14. D. Garland, 'The Concept of a Moral Panic', 4 Crime Media Culture 9 (2008), 17. 
mobs live in the very circumstances that are most likely to give rise to the, also sexual, abuse of children; therefore, such actions are related to a feeling of guilt. ${ }^{15}$ Ironically, paedophilia itself may be a condition associated with poor childhood conditions. ${ }^{16}$

Furedi and Garland agree that in its quality of uniting all sections of society panic over child abuse is a different or indeed a genuine moral panic, not one of periodic outburst but a permanent regime of vigilance, comparable with that of the Medieval witch-hunt. Furedi concludes that as throughout history, the security of children has relied on adults' assuming responsibility for their welfare, and the mistrust that now envelops intergenerational relations threatens to discourage male adults from assuming this responsibility: 'Arguably, the disengagement of many adults from the world of children represents a far greater danger than the threat posed by a (thankfully) tiny group of predators. ${ }^{17}$

That those convicted of a sex offence against children serve as the scapegoat also for other groups targeted by social control is, for example, demonstrated by the widespread need for authorities to protect them from other inmates in (remand) prison. ${ }^{18}$ As the unique moral status of the sacred child is a narrative beyond discussion, 'any opinion can be justified by simply referring to children, and without having to explain why and how children justify it' ${ }^{19}$ It explains why Furedi observes that campaigners who are usually vigilant about encroachment on civil liberties when it comes to new anti-terrorism laws have appeared indifferent to the vetting of millions of adults under different schemes designed to police those who work with or come into contact with children. ${ }^{20}$ Since through these dynamics, of all the targeted groups, sex offenders seem to be least protected against the advancements of social control, they are rendered to be the most interesting focus of this search for the last legal constraints standing. Cohen already argued that on the level of the administration mass 'moral panic', which the pursuit of folk devils can evoke, influences legislation and policy-making. ${ }^{21}$

In addition, there are other arguments for this limitation in scope. As the deviance of sex offenders is often enveloped in the medical model, ${ }^{22}$ similarly to the group of mentally disordered, the interlinking of such discipline with the notion of 'risk' as used in assessments, primarily by mental health practitioners, particularly leads to

15. T. Dalrymple, Spoilt Rotten. The Toxic Cult of Sentimentality (2010).

16. Not just through what is called the cycle of abuse, but also through a sign of lack of (also physical) growth. Physical height is a manifestation of in utero and childhood conditions, and pedophilic individuals have generally been reported to be of lesser height. I.V. MCPhail and J.M. Cantor, 'Pedophilia, Height, and the Magnitude of the Association: A Research Note', 36 Deviant Behavior 288 (2015).

17. Furedi (2016), above n. 12, at 209

18. E.g. Dalrymple, above n. 15.

19. A. Meyer, The Child at Risk: Paedophiles, Media Responses and Public Opinion (2007), at 60.

20. Furedi (2016), above n. 12, at 207

21. Cohen (1972), above n. 9.

22. Compare Laws, above n. 7, chapter 4 . serious ethical and human rights implications. ${ }^{23}$ Moreover, different, for example, from the group of terrorists that is targeted before becoming first offenders, the nature of the (potential) harm by sex offenders is such that measures of control are often concentrated postsentence to avoid re-offending. As these are usually measures of a preventive nature - as the served sentence has already addressed retributive demands - and subsequently often of indeterminate duration, both of these characteristics invoke particular legal theoretical discussions.

\subsection{Focus on Post-Sentence Control in the Community through Supervision}

Just as sentences aiming at the right to liberty can be carried out through custody or within the community, preventive post-sentence measures can be divided in broad terms into control through custody and control in the community. In instrumental criminal justice terminology, they can be divided into schemes of preventive detention and of supervision, and from the civil rights side, the division can occur as deprivation of liberty and restriction of liberty. Much of the current international critical scholarly discussion focuses on preventive detention. ${ }^{24}$

First of all, this is to be understood in consideration of its presumed more invasive character. But perhaps Stanley Cohen begs to differ. Probably the most prominent shift in social control he observed already in 1985 was that from incarceration to community control. He found these alternative methods 'not necessarily more humane and, indeed, they might be less humane by disguising coercion, increasing invisible discretion or (for the mentally ill) simply dumping deviants to be neglected or exploited'. ${ }^{25}$ He discerns that decarceration was a seemingly benign initiative in service of diminishing the discretion of institutions and a search for rehabilitation, while in fact it was mainly a response to fiscal pressures and a retrenchment of welfare policies. Recently, the empirical evidence to support part of this claim was delivered in the finding that, at least in Europe, community sanctions have not truly served as an alternative for imprisonment, but rather as a supplementary sanction. ${ }^{26}$ A comparable dynamic is believed to be true for the more recent alternative of electronic monitoring. ${ }^{27}$ This is part of the explanation for the current prison overcrowding, according to the Council of Europe. ${ }^{28}$ As

23. B. McSherry, Managing Fear: The Law and Ethics of Preventive Detention and Risk Assessment (2014)

24. E.g. P. Keyzer (ed.), Preventive Detention: Asking the Fundamental Questions (2013); M. Caianello and M.L. Corrado, Preventing Danger: New Paradigms in Criminal Justice (2013).

25. Cohen (1985), above n. 1, at 38

26. M.F. Aebi, N. Delgrande \& Y. Marguet, 'Have Community Sanctions and Measures Widened the Net of the European Criminal Justice Systems?', 17 Punishment \& Society 575 (2015).

27. See the recent special issue on electronic monitoring: $M$. Nellis and $M$. Martinovic, 'Editorial', 34 Journal of Technology in Human Services 1 (2016); and A. Hucklesby, K. Beyens, M. Boone, F. Dünkel, G. Mclvor \& $\mathrm{H}$. Graham, Creativity and Effectiveness in the Use of Electronic Monitoring: A Case Study of Five Jurisdictions, EMEU-Report (2016).

28. Council of Europe, White Paper on Prison Overcrowding (2016). 
schemes of supervision may be marketed with a similar rationale of being an alternative for preventive detention, similar scepticism is warranted.

But probably a more important reason why critical discussion has focussed on detention instead of supervision is that the 'tools' for discussion from both a theoretical and human rights perspective are more readily at hand, while discussing supervision requires exploring more of a grey area.

In sentencing theory, discussions on preventive schemes focus first on the debate on the sentencing goals of punishment versus prevention and the relation with the (severity of the) original offense. An exemplary finding from the Canadian Supreme Court was that a ten-year term of community supervision appended to the end of a sentence under a 'long-term offender' statute could be validated on the grounds that the supervision was not punishment. ${ }^{29} \mathrm{~A}$ second line along which, from a theoretical perspective, the issue may be approached is through the principles of proportionality and least intrusive means. As supervision is predominantly considered to be a less severe sanction, it raises very little discussion in comparison with the vast literature on preventive detention.

From an international human rights perspective, especially the right to liberty and the subsequent prohibition of arbitrary deprivation of liberty, laid down in many relevant conventions, ${ }^{30}$ is the focus of discussion. Again exemplary is that in her thorough, thirty-plus-page analysis of the international human rights framework on preventive schemes, McSherry can only devote two sentences to restriction of liberty:

Supervision orders in relation to offenders also raise concerns about the violation of the right to liberty, but have not been subject to the same level of scrutiny at the international level as preventive detention regimes. Presumably, these orders can be justified if there are sufficient procedural safeguards attached to them. ${ }^{31}$

Therefore, this research is aimed at trotting on this unexplored terrain to find where the borders of social control in the community are drawn, if any are in fact drawn. For example, which of the presumed procedural safeguards that McSherry mentions actually need to be in place? In keeping with Cohen's increased intensity of control directed at 'former deviants', this research focuses on post-sentence or post-custody supervision schemes, although pre-crime or other post-crime (also pre-trial) schemes may be addressed indirectly.

29. $R$ v. LM, 2 SCR 163 (2008).

30. Art. 9 of the Universal Declaration of Human Rights; Art. 9 of the International Covenant on Civil and Political Rights; Art. 14 of the Convention on the Rights of Persons with Disabilities; Article 5 of the European Convention on Human Rights; Art. 7 of the American Convention on Human Rights; Section 7 of the Canadian Charter of Rights and Freedoms; the 14th amendment to the United States Constitution; Section 22 of the New Zealand Bill of Rights Act 1990.

31. McSherry, above n. 23, at 185
Of course, supervision is not the only legal framework for post-sentence social control of sex offenders, as, for example, free-standing restriction orders and registration and community notification are other possibilities. Since comparative research showed that the severe schemes of registration, notification and restriction orders, virtually limiting the possibilities to live to designated compounds or literally somewhere under a bridge, are especially American phenomena unmatched in other jurisdictions, ${ }^{32}$ free-standing orders of this kind are not focused on. However, supervision orders generally come with conditions of many different kinds, including restrictions such as location bans, possibly enforced through electronic monitoring, or other measures of control that could also be imposed independently or through other legal frameworks, such as a treatment order. Another increasingly common example of such a condition is the obligation to undergo DNA-collection, which has human rights implications of its own. Falling outside the scope of this study are so-called collateral consequences of the conviction of a sex, or even any other, offence. These are the additional civil or administrative actions, which are triggered by the conviction - although some of these may be part of the conviction. They could include loss or restriction of a professional license, ineligibility for public funds including welfare benefits and student loans, loss of voting rights, loss of residential status for immigrants, etcetera. They could also be indirectly triggered by the impossibility of receiving a certificate of good conduct, necessary for many of the above-mentioned rights or privileges. In the United States, these collateral consequences can be so severe that they have been compared to the historical concept of 'civil death'. 33

Next to the legally organized consequences are, of course, the societal consequences of the stigma of being a sex offender, which will form a more hidden barrier for many necessary requirements for true reintegration, such as finding a job. Since social life involves presenting to others information pertaining to self, individuals perceived as deviant experience particular problems in the demanded 'impression management' because the stigma can discredit their social identity. ${ }^{34}$ Even though falling outside Cohen's definition, the stigma and its consequences can easily be labelled an instrument in the wider definition of social control. Coping with the stigma itself may even be part of the explanation for the fact that sex offenders demonstrate heightened levels of negative emotions, traumatic experiences, mental health issues, and emotion disregulation, with its subsequent treatment needs. ${ }^{35}$

32. See Laws, above n. 7

33. G.J. Chin, 'The New Civil Death: Rethinking Punishment in the Era of Mass Conviction', 160 University of Pennsylvania Law Review 1789 (2012).

34. Laws, above n. 7, at 15 shows examples of that and refers to E. Goffman, Stigma: Notes on the Management of Spoiled Identity (1963).

35. J. Willemsen, V. Seys, E. Gunst \& M. Desmet, "“'Simply Speaking Your Mind, from the Depths of Your Soul": Therapeutic Factors in Experiential Group Psychotherapy for Sex Offenders', 16 Journal of Forensic Psychology Practice 151 (2016). 
1.4 Focus on Comparing Jurisdictions in Europe As it is argued that there is no firm framework of international human rights law with regard to supervision, while theoretical notions underlying criminal law are generally at the disposal of (federal, national or regional) legislators or courts to be picked at their convenience, this research seems to require a bottom-up approach and the exploration of sentencing theory, legislation and practice within individual jurisdictions. Obviously, a comparative approach is needed in order to find generalities and draw conclusions above the national level.

To have at least some guidance from an international law perspective, for the purpose of this research, jurisdictions from within Europe were chosen. Article 5 of the European Convention on Human Rights is considered a well-elaborated provision on the right to liberty. ${ }^{36}$ First of all it immediately shows that the right is not absolute and can be breached in accordance with a procedure prescribed by law and in the mentioned list of cases - relevant are the conviction by a competent court $(1, a)$ and detention of persons of unsound mind, alcohol drug addicts or vagrants $(1, \mathrm{e})$. In addition, in the subsections of the article and in the case law of the European Court of Human Rights (ECHR), many safeguards concerning the deprivation of liberty are also deducted from it. ${ }^{37}$ Next to the principles of legal certainty (accessibility and foreseeability) and no arbitrariness, for example the right to have the lawfulness of the detention speedily examined by a court and the right to compensation for unlawful detention. For the purpose of this research, the most relevant elaboration of Article 5 was established in the case of Guzzardi v. Italy, where the ECHR considered that

the difference between deprivation of and restriction upon liberty is nonetheless merely one of degree or intensity, and not one of nature or substance' and that 'the process of classification into one or other of these categories sometimes proves to be no easy task in that some borderline cases are a matter of pure opinion. ${ }^{38}$

Guzzardi was placed under special supervision with compulsory residence on the island of Asinara, with

36. See McSherry, above n. 23, at 178 .

37. See ECHR, Guide on Article 5 of the Convention. Right to Liberty and Security, Council of Europe/ECHR (2014).

38. ECHR, Guzzardi v. Italy, Appl. No. 7367/76, 06-11-1980. many other restrictions. ${ }^{39}$ On the basis of the actual situation on the island and cumulative and combined factors like the extremely small size of the area where he was confined, the almost permanent supervision to which he was subject, the all but complete impossibility for him to make social contacts and the length of his enforced stay resulted in the consideration that on balance the case was to be regarded as one involving deprivation of liberty. The court noted, 'In certain respects the treatment complained of resembles detention in an “open prison" or committal to a disciplinary unit.' It subsequently found that there was a breach of Article 5, sub 1 because on the basis of prevention there was no ground for deprivation of liberty. Even the attempt of the state to classify this mafia member as a vagrant (sub 1, under e) failed.

Of course, this decision gives rise to testing supervision frameworks on the safeguards of Article 5, as in an individual case where the restrictions are so severe that they may be considered deprivation of liberty. In literature also, the fact that a breach of conditions in a supervision framework may lead to 'recalled' detention is mentioned as an additional rationale for this test. ${ }^{40}$ As the jurisdictions in this comparative research are all subject to the European Convention on Human Rights, their attention for this consequence in the legislative process and in judging individual cases of supervision is of particular interest.

Even though restriction of liberty is not part of the Convention as such, in the additional Fourth protocol, Article 2 provides for the right to liberty of movement and freedom to choose residence. As these rights are qualified rights, they may be subject to restrictions if provided by law and necessary in a democratic society, for example, to prevent (re-)offending. Of the five jurisdictions in this comparison, Spain and the United Kingdom signed but never ratified this protocol, mainly on

39. In its decision, the Court further directed that the applicant should, see n. 38:

- start looking for work within a month, establish his residence in the prescribed locality, inform the supervisory authorities immediately of his address and not leave the place fixed without first notifying them;

- report to the supervisory authorities twice a day and whenever called upon to do so;

- lead an honest and law-abiding life and not give cause for suspicion;

- not associate with persons convicted of criminal offences and subjected to preventive or security measures;

- not return to his residence later than 10 p.m. and not go out before 7 a.m., except in case of necessity and after having given notice in due time to supervisory authorities;

- not keep or carry any arms;

- not frequent bars or night-clubs and not take part in public meetings;

- inform the supervisory authorities in advance of the telephone number and name of the person telephoned or telephoning each time he wished to make or receive a long-distance call.

40. E.g. M. Van der Wolf and M. Herzog-Evans, 'Supervision and Detention of Dangerous Offenders in France and the Netherlands: A Comparative and Human Rights' Perspective', in M. Herzog-Evans (ed.), Offender Release and Supervision: The Role of Courts and the Use of Discretion (2014), 193. 
the grounds that they contained rights for migrants that were not fully provided for in domestic law. ${ }^{41}$

The comparison will therefore show whether this makes any difference with regard to supervision frameworks for (sex) offenders and also whether all sorts of soft law from European alliances is given a different significance. Not only do different jurisdictions have different room for manoeuvre or use different interpretations of the leeway received from the ECHR, but because they do not share (exactly) similar legal traditions, theoretical discussions about a similar phenomenon may actually be very different both in perspective and in outcome. The aim of this research is therefore to explore legal constraints on the social control of sex offenders through frameworks of supervision from a comparative perspective, focusing both on constraints from a national theoretical or doctrinal perspective and the interpretation of ECHR constraints in national legal practice.

The jurisdictions that are part of this comparative project were selected first because they all share relatively recent or current legislative initiatives to safeguard society against alleged dangerous (sex) offenders through supervision frameworks. In addition, these jurisdictions represent different legal traditions. Of course, England (along with Wales) stands out with its common law tradition and absence of a codified sentencing system. But while other jurisdictions share the continental European civil law tradition, these jurisdictions have different traditions in sentencing dangerous offenders. Germany and the Netherlands have a very long and continuous tradition of a twin-track system of criminal sanctions penalties and safety-measures - dating back to the grand Classical versus Modern school debate around the turn of the twentieth century and the authoritarian period in the 1920s and the 1930s. Nevertheless, in terms of legal frameworks for supervision, their systems show many differences. Whereas Spain had a similar history, safety measures aiming at 'social defense' were misused during the Franco regime and thereafter in the 1970s discredited and abolished. Safety measures only reluctantly reappeared in the 1990s. In France, on the other hand, the 1970 s were the heydays of the Defense Sociale Nouvelle, leading to the adoption of safety measures. The specific histories of these relatively more novel twintrack systems will also show to affect their development. As the core of this research, from all five jurisdictions criminal law scholars with an expertise in sentencing have written papers on this topic on the basis of a similar outline to aid the comparison. In alphabetical order of the respective countries, Nicky Padfield wrote the English perspective, Martine Herzog-Evans the French, Bernd-Dieter Meier the German, Sanne Struijk and Paul Mevis the perspective from the Netherlands, and Lucia Martínez Garay and Jorge Correcher Mira the Spanish. Their 'country reports' are the other contributions to this special issue. Up to this point, this paper has provided the background, relevance and approach of

41. H. Keller and A. Stone Sweet, A Europe of Rights, The Impact of the ECHR on National Legal Systems (2008), at 398. this research by means of an introduction. From here on, the paper will present a comparative analysis of the findings in the other papers. Evidently, not all the contents in those papers will be reproduced in this analysis nor will references be repeated; for further information, one will have to turn to the individual contributions. The focus will rather be on the relevant differences or generalities for the aim of finding the possible legal constraints that seem to be in place to keep the social control of sex offenders in the community in check. Nevertheless, any reader who wishes to be informed in detail on the situation in the respective jurisdictions is first requested to read the other contributions and then return to the remainder of this paper. The analysis presented hereafter follows the outline that can also be observed in the other contributions. Both the questions asked and the different, or comparable, answers will be highlighted and discussed - without the aim of a complete overview. In asking scholars to write the country reports the comparison is intended to go beyond description into the realm of criticism, as a means to add to the debate of this under-debated topic.

\section{Comparative Analysis}

\subsection{Cultural Context, Legislative Overview and Framework for Evaluation}

In all the country papers, a similar hardening of the attitude towards sex offenders over recent decades is described. As a starting point for the moral panic concerning paedophiles (in England) in the introduction, the 1980s were identified, but legislative responses to sex offenders seem to follow from the 1990s, with England and Wales, Germany and France as 'early responders'. On the basis of this growing support base for measures directed at this group, in keeping with Cohen's theory of moral panic all authors report a (less or more implicit) connection between legislative activity and specific examples of societal upheaval or media controversy surrounding sex offenders, for example, committing a (new) offence or re-entering the community. While these are generally controversies at the national level, especially in the neighbouring countries the Belgian Dutroux case, discovered in 1996, is reported to have had a transnational impact on awareness regarding the possible severity of sexual offences towards children and subsequent legislation. A higher rate of sex offenders in prison, like in several of the jurisdictions, may also just be related to this increased awareness, leading to more reporting of such crimes or priority in policing.

In the context of the arsenal of measures of social control directed at sex offenders, registers are in place in certain countries. In England since the 1997 Sex Offenders Act, in Germany, for example, on a State level, and in Spain since 2015, especially directed at providing information for determining the possibility of working (with minors) after release. These provisions confirm the stigma of sex offenders within the broader 
group of offenders. In theory, in all countries the mental health system may be used to control (potential) sex offenders when meeting the criteria for the respective measures, possibly also as a result of the fact that the criminal justice system and mental system are often interwoven inter alia through placement provisions. Because of a lack of statistics this has to remain a hypothesis for now. Schemes such as exist in some US states that aimed at preventive detention of post-sentence sex offenders through mental health law do not seem to be in place. ${ }^{42}$ However, a German act under civil law from 2010 (Therapy and Placement of Mentally Disturbed Violent Offenders Act) shows similarities. It was meant as a makeshift after the retroactive application of indefinite post-sentence preventive detention was interpreted by the ECHR as amounting to the retroactive imposition of a heavier penalty incompatible with the convention. The act allows placement in closed institutions for those considered to be of unsound mind and if there is a high probability that they will affect the life, personal integrity, freedom, or sexual self-determination of others so that their placement is considered necessary for public protection.

It is recognized that legislative changes directed at sex offenders include those in substantive law increasing the criminalization of various forms of sexual conduct, sometimes distancing the harm principle in favour of a more moral conception of criminal wrongdoing. Possession of virtual child pornography may be an example thereof, and its facultative status with regard to criminalization in treaties from the Council of Europe, seems to recognize this doctrinal vulnerability. ${ }^{43}$ The widening scope of sexual offences is often accompanied by increasing the possible penalty for such offences. In that sense, the increased punitivity of sex offences is merely part of the wider development in criminal politics in the researched countries, explained in the Spanish contribution as 'punitive populism'. The term refers to the widespread idea that these legislative reactions are only responding to the societal upheaval, but not the real problems and needs concerning criminal policy, which are obscure anyway by lack of a serious analysis or empirical evidence. Most of the authors not only report that this has evoked much doctrinal resistance, but also point out that this is directed less at preventive supervision as neither explicitly punitive nor detention.

Turning to legal frameworks (partly) aimed at preventing (also) sexual reoffending in the community, in general five types of frameworks can be distinguished. The first is through community-based punishments or release on parole/conditional release of a sentence of imprisonment. The second, in the continental jurisdictions that separate punishment from (safety) measures in doctrine, is through the imposition of a conditional/

42. See J.S. Blackman and K. Dring, Sexual Aggression against Children. Pedophiles' and Abusers' Development, Dynamics, Treatability, and the Law (2016), chapter 10.

43. Council of Europe, Convention on the Protection of Children against Sexual Exploitation and Sexual Abuse (2007/2010) and Convention on Cybercrime (2001/2004). suspended measure of often post-sentence preventive detention or a conditional release from preventive detention (including extensive frameworks of leave). The third is, in jurisdictions with a similar doctrine, independent measures of often post-custody or even post-sentence supervision under criminal law, including high-intensity and extended supervision after early release. The fourth is civil preventative orders (in some jurisdictions called the realm of administrative law); in the jurisdiction that does not have (safety) measures as a sanction distinct from punishment, such as in England and Wales, these orders seem to serve as an alternative. The fact that breaches of these orders are criminal offences demonstrates that. The fifth, only in England and Wales, is post-sentence supervision under MultiAgency Public Protection Arrangements (MAPPA). These are 'simply' arrangements between police, probation and prison services to coordinate the management of dangerous offenders in the community. Based in legislation, the formulated duty to cooperate for institutions involved in providing health, housing, social services, education, social arrangements, employment and electronic monitoring includes a legal basis for supervision and control post-release and even post-sentence.

That the common law jurisdiction of England and Wales does not have a criminal or sentencing code is probably partly to blame for the custom in the last decades to create and adopt in a high-frequency new 'acts', named after the objective: Sex Offenders Act 1997; Sexual Offences Act 2003; Criminal Justice Act 2003; Criminal Justice and Immigration Act 2008; Legal Aid, Sentencing and Punishment of Offenders Act 2012; Offender Rehabilitation Act 2014; Anti-Social Behaviour; Crime and Policing Act 2014; etcetera. The English contribution shows that new legal frameworks are created and existing frameworks often adapted, for example, with regard to different types of sentences of indeterminate custody as well as specific civil preventative orders for sex offenders, such as Sexual Harm Prevention Orders (SHPO) and Sexual Risk Orders, which in 2015 replaced the somewhat narrower Sexual Offences Prevention Orders and Risk of Sexual Harm Orders. In the French contribution nonetheless, even though historically one of the frontrunners in the codification of law, a similar legislative 'frenzy' is presented. The difference with England and Wales is, however, that all these adaptations are directly visible in the current code, while over the channel it is even difficult for scholars to make out which elements of acts are still applicable and which have been altered by later acts. In France, a 'true life' sentence was created in 1994 after a paedosexual killing. The Dutroux case triggered the enactment of 'socio-judicial supervision' (suivi socio-judiciaire - SSJ) in 1998, consisting of mandatory treatment and supervision both possible as a stand-alone community sentence and post-custodial supervision. A decade later, four 'safety measures' had been added to the arsenal: 'judicial safety surveillance of dangerous offenders' (Surveillance judiciaire des personnes dangereuses - SJPD), 'GPS-electronic monitoring' (Placement sous surveillance électroni- 
que mobile - PSEM), 'safety surveillance' (Surveillance de sûreté - SS), and 'safety detention' (Rétention de sûreté - RS), followed in 2014 by a measure focusing on diminished responsible mentally disordered offenders, some of whom were thought to be sex offenders.

As the German sanctioning system has long and continuously had safety measures in place with preventive detention (Sicherungsverwahrung) and supervision (Führungssicht), the legislative changes that followed from 1998 (with the Act to combat sexual offences and other dangerous offences) onward aimed at adapting these provisions generally to widen their scope of applicability or intensifying the possible control. The supervision is in fact a form of high-intensity and extended parole for persons with a high-risk prognosis after a prison sentence or preventive detention of a certain length. Since 1998 , it is an indeterminate measure as before it was restricted to a maximum of five years. Also since then, the constraints for the imposition and execution of supervision are lower in the case of convicted sex offenders than they are in other cases. While supervision is regularly put into operation upon release from prison after having served at least two years, it is only one year in the case of sex offenders; and the duration of supervision may be extended for life in the case of convicted sex offenders (and a second, very small group of offenders) if the offender has been sentenced to two years of imprisonment and after release either violates a direction or 'other specific circumstances give reason to believe that there may be a danger to the general public by the commission of further serious offences'. These legislative changes have created an exceptionally weaker legal position for convicted sex offenders in comparison with other offenders.

In the Netherlands, the safety measure of preventive detention for diminished responsible offenders has similarly been in place since what is called the authoritarian period in the 1920s and 1930s. As the mental disorders considered eligible for imposition of such an entrustment order (Terbeschikkingstelling - TBS) are defined in broad terms, it has always been the sanction to harvest sex offenders considered dangerous. Different from Germany, there has never been an indeterminate standalone safety measure of supervision in place - a fixed and short-term location or contact ban order was enacted in 2012 - until in 2015 the order of long-term supervision, continuing after prison or a TBS-order, was adopted by parliament. Up until now (November 2016), the order has not been enacted. As dangerous offenders were considered to be in the TBS-system, the need for supervision in the community has been organized through an extensive system of leave and the instalment of conditional release in 1997, the maximum term of which has been changed from three to nine years in 2007, while the same adopted act of the stand-alone measures also contains the possibility of the unlimited prolonging of conditional release from TBS, as well as that of conditional release from prison.

In Spain, although the punitivity of sex offences and the evolution of a new twin-track system had been on the rise since the mid-1990s, some incidents in the mid-2000s caused enough alarma social to also adopt a supervision order. In 2010, the safety measure of 'supervised release' was enacted for post-prison control of sex offenders and terrorists.

In order to find the current legal constraints governing supervision, the authors of the respective countries were asked to evaluate the legal frameworks for post-sentence supervision in their jurisdiction both de jure and de facto in light of the national legal theory doctrine on sentencing, the principles of proportionality and least intrusive means, and the national position on the human rights framework of the ECHR.

\subsection{Evaluation in Light of Sentencing Theory}

In the schemes this study focuses on, three elements in particular raise questions in light of sentencing theory: first of all the fact that they are mainly post-sentence, second that they are often indeterminate, and third that they merely consist of restriction of liberty.

Concerning the first question, in the English perspective, Padfield raises the question why public protection justifies post-sentence 'punishment'? 'What, in fact, do we mean by "post-sentence" punishment - if the offender is still being "controlled", should this be considered as post-sentence or as part of the punishment, part of the sentence?' In this study, England and Wales is the only jurisdiction that has not adopted at some point in history a twin-track system of sentencing in which dogmatically punishment is regarded as dominantly retrospective and retributive, while safety measures are dominantly prospective and preventative in nature. It explains the questions raised, which on the continent would be replied with a simple statement: 'a safety measure is in theory not considered punishment'. Obviously, the English rejoinder would be that you could give it a different name on paper, but 'if it looks like a duck, swims like a duck, and quacks like a duck ...'. Indeed, the theoretical notion that the experienced suffering in preventive detention is different from that in prison as it is not 'intended' will sound ridiculous to the detainee at hand. The English perspective also shows that the discussion on retribution versus prevention is predominantly drawn into that on the purposes of sentencing leading to a variety of indeterminate sentences, while for exclusively preventive measures civil orders can come into play. Again for the 'offender', the restrictions will feel similarly punitive and criminal in nature.

In the German perspective, Meier explains how in the Classical school tradition in continental European jurisdictions punishment was governed by the guilt principle and thus administered to the extent of guilt. Conditional/suspended sentencing and conditional release/ parole were among the first triumphs attributed to the Modern school around the turn of the twentieth century, whose deterministic view of man shifted the focus prospectively to prevention and rehabilitation. Even though the Modern school was internationally united in the Internationale Kriminalistische Vereinigung, the way 
in which a compromise was formed with the Classical school through a twin-track system differs between the continental jurisdictions. In the Netherlands, for example, precondition for the Classical school to accept the compromise was to only enact indeterminate preventive detention for mentally disordered offenders who could not be held (fully) responsible for their crimes. Other than in Germany and France, the Dutch do not have a measure of indeterminate preventive detention for fully responsible offenders, although in practice the disorder criterion is interpreted in a way that, for example, regarding sex offenders more or less the same sort of people fall under its scope. In Spain, a similar approach seems to have been taken in the 1990s, when the twintrack system was re-introduced with historical lessons learned. The aim of the introduced measures was rehabilitation rather than security, the duration was subject to strict limits of proportionality (with the alternative prison sentence as reference) and the execution order was safety measure before (and counting as) the prison sentence.

This hybrid between the two tracks - a blurry system also observed in France - corresponds with the Dutch pragmatic changes to the system over the past century, through which sentences can now be disproportionate to the extent of guilt on grounds of prevention and safety measures may be terminated as disproportionate to the severity of the offence and corresponding prison sentence. So when it was argued in Spain that the long lack of safety measures - like in England and Wales - had blurred the concept of punishment, the Dutch showed that both tracks can be blurred while existing next to each other. From a dogmatic perspective, Germany seems to remain as the most distinct twin-track system trough upholding the principle of punishment to the extent of guilt, even though for measures the law requires 'proportionality to the seriousness of the committed offence or the expected offence'.

The indeterminacy of the frameworks is self-evident in a strict twin-track system because the duration should be proportionate to the aim of public protection and other than guilt dangerousness is not determined retrospectively. All authors mention, however, the limited validity of risk assessment, which seems to call for caution concerning the indeterminate duration of a measure. Emphasizing the seriousness of the committed offence may also be done out of diagnostic deliberations as an expression of the robust empirical finding that past behaviour is still the best predictor for future behaviour. Procedural safeguards, such as judicial review on prolongation, are generally also part of the counterbalance to that uncertainty. But in Spain, for example, the framework for supervision is deliberately not indeterminate, again safeguarding proportionality from the perspective of legal protection against the (experienced misuse of) State power. In the Netherlands, the measure of long-term supervision would be the first safety measure of indeterminate duration not limited to mentally disordered offenders. This has crossed a theoretical border in a sense that the label of mental disorder suggests to ensure treatment, which could be considered a positive obligation of effort to avoid the possible indeterminacy. This suggests that the fact that supervision is not considered as invasive as detention may be used as an argument to cross existing theoretical borders. The Spanish authors seem to acknowledge this suggestion as well.

Even without the requirement of mental disorder, rehabilitative aims are reported in several jurisdictions as a complimentary justification for safety measures next to public protection (and treatment). Of course this does not mean that rehabilitative or treatment-considerations may determine the continuation or termination of the measure, as in the past has been the case in the Netherlands. In jurisdictions like Germany and Spain, rehabilitation seems to be most strictly engrained in law as the objective of the sentencing system. All authors express the concern, however, that in practice supervision will be used to control more than to treat or rehabilitate given the fact that the latter is much more costly in terms of financial and personnel resources.

The prospective focus of safety measures is not only reported - most strongly in the French contribution by Herzog-Evans - to be prone to conflict with proportionality, but also with legality. The element of prohibition of retrospective implementation of law is mentioned, but the ECHR has limited the relevance of Article 7 in regard to 'harsher punishment' as not to include changes to provisions regarding the execution of a sanction (at the expense of the individual undergoing that sanction), for example, in the case of Kafkaris $v$. Cyprus (2008). More important is the question whether safety measures may be imposed because of dangerousness without an established offence or after serving a sentence for an established offence. Among the mentioned English preventative orders based on the risk of sexual harm, the former and latter are observed because a conviction is not always required but merely an 'act of a sexual nature', while the order may be imposed free standing, even after the sentence. As these orders are civil in nature, some high-principled standards of criminal law may be bypassed to an extent, such as a lower burden of proof. In Germany, preventive detention could be imposed post-sentence until the ECHR amended that. For supervision, it is still possible, but in general supervision applies by default after a prison sentence or preventive detention of a certain length. Another aspect of the encounters of the Sicherungsvermahrung with the ECHR is also related to legality in way; as the safety measure proceeds for a long time, the established offence is being distanced in a way that it gradually diminishes as a justification for further deprivation of liberty. As related to Article $5 \mathrm{ECHR}$, this will be addressed in paragraph 2.5. Again this suggests that for supervision, these theoretical borders may be crossed more easily.

The fact that frameworks of supervision are considered restriction of liberty instead of deprivation of liberty has not yet raised other theoretical questions than the above-mentioned suggestions that some theoretical con- 
straints may be less rigid for a less intrusive measure. In the German perspective, Meier, for example, notes that the depth of intrusion of a measure has to match the degree of dangerousness so the risk requirement may be less high for supervision than detention. Apart from Cohen's opposite view on the intrusiveness on both frameworks, it is important to note that supervision may involve deprivation of liberty. For example, treatment in a mental hospital may be a condition. Conditions are generally not coerced but enforced through sanctions on breaching conditions, with (recall to) deprivation of liberty as the sanction. And with recalled deprivation of liberty, warnings of backdoor sentencing, double or additional punishment surface in doctrine in the respective countries. In the English perspective, a case is mentioned in which a breach of a civil order was punished with initially four and after appeal three years, which Padfield considers putting the lie to the distinction between civil and criminal sanctions.

\subsection{Legal Frameworks for Indeterminate}

Supervision: Evaluation of Proportionality

The principle of proportionality regarding measures is described in the German perspective as consisting of four elements: legitimacy of the aim, suitability to achieve the aim, necessity to achieve the aim, and adequacy considering the competing interests. The third element of necessity entails that the aim cannot be reached by less intrusive means, which are at hand in the arsenal of social control, and will be addressed in the next paragraph. The legitimacy of the aim of public protection is not in question in any jurisdiction, and so in this paragraph mainly the elements of suitability and adequacy are evaluated.

The suitability of the respective frameworks in achieving the aim incorporates an analysis of their pre-legislative justification. In the introduction, a variety of loose to strong connections to incidents concerning sex offenders that caused societal upheaval has been established as a trigger for legislation. The recent adoption of a supervision order in the Netherlands was strongly related to incidents concerning the re-entry of sex offenders in the community. This seems to explain why novel restrictions as a ban to live in certain areas or a duty to move are part of these provisions. The added value of the possibly life-long order was also explained by the government with regard to the offence of possession of child pornography, which due to proportionality deliberations could only lead to preventive detention for a maximum of four years (without the option of an extension for conditional release). In the Dutch contribution, the authors question the proportionality of the order related to the problem referring to the expected low numbers of execution of the order, an expected low success rate and the costs of required resources, in particular related to the empirical finding that societal upheaval concerning re-entry of sex offenders only occurs in a small minority of cases and generally disappears quickly.
The enactment of supervised release in Spain in 2010 was in part connected to specific sexual offences. It was aimed at terrorists and sex offenders and later widened to apply to certain violent offenders. It was scrutinized both for being unnecessary given the low level of violent and sexual offending rates in Spain and for being too soft and thus ineffective in protecting the public against sex offenders. The French SSJ was justified through the somewhat opposing objectives of neutralisation, rehabilitation and treatment. Whereas the first two are fought over by different political views, there is consensus about the idea that sex offenders, the initial target group, need treatment, more so than the group of violent offenders which was added later. The order and following safety measures could also be deemed necessary because in France the sentences for sex offenders are quite lenient, with an average of eight years for rapists. In England, as mentioned, some of the acts in recent history changing the sentencing system as well as some of the civil preventative orders are - also by name - designated for (future) sex offenders. In Germany, the supervision order has known a longer history, but the data suggest that sex offenders form a large part of the population.

As all the above-mentioned frameworks of supervision are aimed at prevention, the suggestion is that sex offenders pose a significant danger to society. All authors consider dangerousness a dangerous concept because of the limited predictive validity of (state-ofthe-art) risk assessment. Empirical findings are presented to suggest that risk of reoffending is overestimated in general, through methodological flaws in assessment (such as a low base rate) or in reaction to societal upheaval in case of reoffending (false negatives). The assumption that sex offenders are at a higher risk of reoffending than other offenders cannot be validated by empirical data, which are subsequently lacking in prelegislative justifications. Our knowledge does not yet distinguish amongst the group of sex offenders the characteristics of those actually posing a high risk for reoffending. Therefore, harsher restrictions on the broad group of sex offenders than on other offenders do not seem to be proportionate in terms of suitability to the intended aim of public protection. Moreover, all authors of the country contributions suggest that this double overestimation of risk and the plausible high number of false positives as a consequence is an additional problem in that respect.

The adequacy of the frameworks of supervision requires weighing the hardships of the individual, or the depth of intrusion of the supervision, against the gains of the public, the likelihood and seriousness of further offences if no supervision would be executed. This evaluation requires both the law in books and the law in action. How is the law defined, in terms of criteria for imposition, duration, the kind of restrictive conditions or directions that can be put in place and the procedural safeguards governing the process? And how are these legal possibilities used in practice, applied in individual cases of sex offenders and with what effect? 
Apart from the exceptions explained in paragraph 2.2, an offence of a certain seriousness is required for most frameworks of supervision. In the French perspective, for example, is spoken of a very restricted list of extremely serious offences. Sometimes, the imposition of supervision is indirectly related to the seriousness of the offence through a requirement of the length of the prison sentence or the preventive detention, like in Germany. This is comparable in the Netherlands although the prison sentence has had to be imposed for an offence against the inviolability of the body, meaning a violent or sex offence. As in Spain, the framework is supervised 'release' - it only applies to offences for which parole is in place and is mandatory for sex offences. In England and Wales, Sexual Harm Prevention Orders are for those who were convicted or cautioned for a 'relevant' offence not necessarily a sex offence - Serious Risk Orders just require 'an act of a sexual nature' - as long as there is a risk for sexual harm. This definition shows that in addition to past behaviour generally a dangerousness criterion is required. In countries with many possible measures, the definition of dangerousness may differ per framework, more or less proportionate to the intrusiveness of the corresponding restrictions. In France, for example, the criterion may either be absent (for SSJ, just committing a violent or sex offence suffices), 'dangerousness', 'particular dangerousness' or a 'proven risk of recidivism'. 'Particular' refers to 'a high probability of recidivism because of a serious personality disorder', and as in France psychoanalysis is still dominant 'perversion' is regarded as a personality disorder and is most often used. 'Proven' refers to expert testimony, but evidence-based risk assessment is neither required nor valued. In Spain, the criterion itself refers to the testimony: 'prediction about the future behaviour of the subject that states that he will probably commit new crimes'. Nevertheless, the law omits to require expert testimony for supervised release. For the German supervision order, a prognosis of high risk is necessary. In England and Wales, before 2015 the criterion for the mentioned civil orders was a risk of 'serious' sexual harm as if there was any other kind. Currently, the definition is risk of sexual harm to the public in the United Kingdom or children or vulnerable adults abroad. In the Netherlands, imposition of the supervision order requires an easily met general public safety criterion, but execution requires risk of recidivism of an offence serious enough for imposition of the order, or risk for 'seriously damaging behaviour towards victims or witnesses.' For this last criterion, only a risk assessment by the Probation Services is needed.

The Dutch criteria show a twofold procedure of imposition by the court at sentencing and a court decision of execution at the end of custody in which the initial duration and specific restrictions are formulated. In Spain, a similar twofold procedure exists, although it is not the Public Prosecutor but the Court for Penitentiary Control (CPC) requesting the execution. In Germany, only as an exception could it be a judge imposing supervision because the main route is by default after the mentioned custodial sanctions. In England and Wales, an SHPO may be imposed at the time of sentencing or on free-standing application to the magistrates' court by the police or National Crime Agency; for a Sexual Risk Order, only the latter situation is available. In France, SSJ is imposed by the sentencing court, while the other safety measures are imposed (after custody) by the judge in charge of the execution of sanctions (juge de l'application des peines - JAP) or a special chamber of the court of appeal.

Concerning the duration of the measure, the distinction must be made between an initial duration and a maximum duration. Spain is the only country in which there is in fact no indeterminate, or possibly life-long, supervision order. The duration of supervised release lasts between one and five years, or between five and a maximum of ten years, depending on the seriousness of the offence. At least annually the CPC should make a proposal to the court to terminate or change the restrictions. In France, SSJ has a maximum duration of ten years for felonies, twenty years for crimes, thirty years by special decision and can be perpetual for lifers. However, through the safety measure of Safety Surveillance supervision can be prolonged for two years and renewed ad infinitum. Concerning SSJ, the JAP decides whether to review the order periodically or to entirely delegate supervision to the probation service. The German supervision can be of determinate duration between two and five years, or indeterminate if there is no cooperation with the treatment and a risk for serious reoffending. With a fixed duration, judicial review is every six months, with indeterminate duration of two years. The Dutch supervision order may be imposed and prolonged for a period of two, three, four or five years, which is then also the term for review. The civil orders in England and Wales are imposed for determined periods with a minimum duration, which may be repeated at the end of that period. At the request of the individual or the police, the court can also order to prolong, alter or terminate the measure.

With regard to the kind of restrictions that can be put in place, the civil preventative orders have no constraints in law. The law requires the individual to notify the police of his or her name and address, including where this information changes. Of the countries in which the restrictions are specified in law, it is ominous that most restrictions focus on control, such as notification, location or contact bans, controlled by electronic monitoring - in France, this is a possible additional safety measure - and labour or housing restrictions. Less restrictions are rehabilitative in nature, like a duty to participate in (possibly clinical) treatment, to do educational programmes or find a job. Paying damages is a kind of restorative condition. Herzog-Evans notes that in France the restrictions are not so different from parole, but the difference with release and most community sentences is that for safety measures no consent is needed, possibly also lowering the rehabilitative effect. Breaching the condition may result in a maximum prison sentence of six months in the Netherlands, one year 
in Spain, three years in Germany and five years in England and Wales. In France, in regard to SSJ the possible sanction on breaching a restriction is pre-determined by the sentencing court and can be up to three years if the initial offence was a felony and seven years if it was a crime. However, the JAP is in charge of implementation and can decide to partially implement the pre-determined sanction.

The fact that sanctions can be combined at sentencing may lead to a situation in which first a prison sentence may be followed by a long period of preventive detention and later supervision. If the prison sentence was short because of the seriousness of the committed offence and extent of guilt, what followed will be considered disproportionate sooner, even though from a preventive point of view the seriousness of a possible further offence is leading. In jurisdictions where orders can be made free-standing, all sorts of concurrence between legal frameworks may occur. In the English perspective, some guidance is given, especially also by a court of appeal decision stating that next to an indeterminate sentence a civil preventative order is generally unnecessary. Nevertheless, the question is raised whether a judge in charge of the execution, like in France or Spain, would be helpful in this respect.

In the literature mentioned in the introduction, it was merely suggested that supervision would not be illegitimate as long as there were procedural safeguards in place. Of course, for impositions during sentencing, ordinary due process principles of criminal procedure regulations pertaining to sentencing will be in place. The twofold procedure in the Netherlands and Spain is itself a procedural safeguard. All countries seem to have possibilities for appeal, recurring and/or the option of demanding judicial review in place in the stage of execution. Imposition after the sentence may require additional safeguards, as is the case regarding French safety measures. One example is the required three layers of risk assessment for most safety measures: (a) by an expert; (b) after a placement of up to six weeks in clinical environment; and (c) by a so-called multidisciplinary commission for safety measures. Probably only in the Netherlands, and England and Wales may evidencebased risk assessment instrument be mandatory. Counter-expertise however is generally only paid for by the government if the court finds it necessary, although in the adversarial system in England and Wales it might be considered more of a right.

These safeguards will be important because in a few contributions studies are mentioned that found that a lack of experienced procedural fairness may actually increase the risk of recidivism (during supervision), just as isolation does, which may be the case if control is not combined with counselling, treatment, social support and a focus on 'the realisation of meaningful lives' instead of 'the prevention of risks', needed for supervision to have the required effect. Therefore, how the legal framework is applied in practice will be more important for the evaluation of adequacy.
Two types of empirical data would be of interest in this evaluation: data on the frequency of application of the supervision orders and data on their effectiveness in reducing reoffending. As the Dutch order has not been enacted yet, no data exist. There are no data for Spain as well, since the order was enacted in 2010 and is imposed at sentencing in combination with custody and executed thereafter. In the other countries where supervision has a longer history, the authors of the contributions complain about a lack of data, nonetheless. However, German data suggest that supervision is imposed more for five years than for two years, revealing that the courts seem to act risk oriented. In France on the other hand, courts seem to be more cautious from the perspective of liberties of the individual. SSJ is far from being systematically imposed on sex offenders. The data also show that with a mean duration of six years paedosexual offenders are longer under supervision than other sex offenders. Electronic monitoring is not often used, but if it is used it is on a sex offender in a large majority of the cases. In a recall study from a few years ago, a figure of 25\% was established. In England and Wales studies show an effect in reducing reconvictions of violent and sex offenders after the introduction of MAPPA. But more recent data show an increase of cautions, reconvictions and/or recall on licence, under MAPPA or with civil orders. This at least seems to suggest a shift towards control instead of support.

In Spain, the biggest concern regarding an effective practice is the lack of a designated authority to carry out the control: 'a supervised release without a supervisor'. This is only one aspect of the lack of adequate resources, urging Martínez Garay and Correcher Mira to say that effective management of sex offenders in the community will only be possible if the legal framework is backed up by these resources. Even though the situation in other countries may not be as desperate, most authors echo this concern. For example, in France, cooperation between the different services is not like under MAPPA.

Especially in France, and England and Wales, the judiciary has aided in drawing borders concerning the proportionality of certain restrictions in individual cases. As suggested by the data, the judiciary is cautious in restricting liberties, although sex offenders are generally the most restricted group, judging by a finding concerning contact bans. However, concerning electronic monitoring administrative courts have urged the prison services to refrain from serious infringements on the private lives of those under monitoring: for example, being awakened several times during the night as a direct result of the poor technology used. Also, bans or controls on use of computers or the Internet are only allowed if it is established that a non-contact sex offence (such as downloading child pornography) has been committed. A similar ruling was made by a court of appeal in England and Wales in 2015. A blanket prohibition on computer use or the Internet access is disproportionate because it restricts the defendant in the use of what is nowadays an essential part of everyday living for a large 
proportion of the public, as well as a requirement of much employment. Moreover, a direction under a civil order relating to activity with children should be justified by demonstrating that the risk is not already catered for by other regulations. In another 2015 case, directions prohibiting contact with minors were too stringent and reformulated to incorporate a clause like 'such as is inadvertent and not reasonably avoidable in the course of lawful daily life'. In a 2010 case, the UK Supreme Court had already ruled that indefinite notification requirements were disproportionate, leading to the possibility of appeal after being on the register for a very long time. However, those under SHPOs may not appeal. In a Dutch case, a civil court in summary proceedings explicitly ruled that two of the restrictive conditions imposed on a conditionally released offender - an area restraining order with associated electronic monitoring for five municipalities - were disproportionate. These rulings suggest that restrictions should be proportionate also as not to hinder rehabilitation too much.

\subsection{Place among Other Sentences and \\ Preventative Measures: Evaluation of \\ Alternative Less Intrusive Means}

Are the legal frameworks for indeterminate supervision, and their practical utilization, considered necessary in addition to all other - possibly less intrusive - alternatives? Especially concerning new legislation of such frameworks, the government should justify that the aim of public protection cannot be reached through existing means. Otherwise, as Struijk and Mevis underline, additional community sanctions are an unnecessary widening and strengthening of the net of social control. As the different characters of the respective legal frameworks for supervision are now known well enough, this paragraph will elaborate on the main alternatives.

As is pointed out in the English and French perspective, despite the existence of alternatives most sex offenders will just pass through prison. As many frameworks of supervision focus on necessary control after custody, the apparent observation is that imprisonment itself does not reduce dangerousness, probably on the contrary. In the Spanish perspective most prominently, a reference is made to studies that show a risk-reducing effect for a significant percentage of sex offenders after rehabilitation treatments received during prison sentence. Nevertheless, in most of the studied countries treatment programmes are not nationally implemented. In France they are, but Herzog-Evans is critical about their lacking of an evidence base. In England and Wales, sex offenders are generally required to do courses, but they mainly go through the system with many queues and delayed advances in placement or hearings. In a case of an indeterminate sentence, it was ruled that such delays breached the 'right' to rehabilitation in showing that there is no longer a present danger. Indeed supervision may be needed less if sex offenders left prison more rehabilitated than is the case now. The Spanish authors consider the lack of rehabilitative programs in deep contrast with their constitutional aim of rehabilitation. After prison, no legal options or programmes are in place other than sporadic initiatives for volunteers like Circles of Support and Accountability, which does have an established preventive effect.

Of course, if the released sex offenders meet the criteria of mental health law, they could be coerced to commitment in a mental hospital and/or medication. As mentioned, a lack of data leads only the hypothesis of sex offenders controlled in that way. In some countries, such as France, through flexible placement provisions it is also possible to place sex offenders in secured mental health facilities during the time of the sentence. This could be used to reduce reoffending risk, but in the Netherlands, for example, this is generally only used as crisis interventions.

Restrictions on liberty in the community can be reached through other legal frameworks. Of course, other criminal sentences than custody may be used as an alternative, like conditional or suspended sentences or release as the most obvious. But in most jurisdictions, accessory sentences also may be imposed (in addition). In Spain, these can be imposed because of dangerousness, and some scholars consider them safety measures. In the German legal system, similar restrictions are possible under police laws, based on the duties of the police to ensure security (or public order) through security law as part of administrative law. The danger must be more concrete than under criminal law, but Meier doubts whether such restrictions are less intrusive. Also in the Netherlands, restrictions are possible under administrative law, but not as restrictive as the supervision order under criminal law.

The recently adopted Dutch supervision order was explicitly justified by the legislator as necessary to fill existing gaps in legislation. As traditionally dangerous offenders are addressed through the TBS-order, possibly also imposed conditionally, it was deemed problematic that TBS has recently been less imposed because defendants refuse to cooperate with the required (personality) assessment. This leads to evaluators refraining from giving an advice, which leads to less impositions even though law allows for imposition, nonetheless. This suggest that dangerous offenders who should be in TBS are now just serving sentences, and therefore the government needed supervision afterwards. The problem, however, is not addressed at its roots. Defendants do not want to receive a TBS-order because the mean length of duration has risen to eight-plus years. Attempts to reduce this length are underway, but the possible result of less 'refusers' is not awaited. Another gap is considered the maximized TBS at four years for non-violent offenders, such as hands-off sex offences. Again, the problem could be solved by abolishing that modality. In terms of less intrusive means, it is interesting that along with the supervision order, the perpetual prolongation of parole after prison for dangerous offenders and the perpetual prolongation of conditional release from TBS preventive detention were adopted. These two changes seem to cover many gaps, and their 
results could have been awaited before introducing the supervision order. Finally, as mentioned the societal upheaval concerning re-entry of sex offenders seemed necessary to address, even though in practice mayors of Dutch towns already use civil proceedings for imposing supervisory conditions on presumed dangerous exoffenders returning to their community. This sometimes works as long as the time for conditional release has expired and the conditions are not too severe. A more severe option under civil law is the mentioned makeshift placement in closed institutions of preventive detainees considered to be of unsound mind, after the ECHR ruled the retrospective post-sentence imposition of their preventive detention incompatible with the convention. The question is, however, whether similar or any other constraints from a human rights perspective seem to control supervision.

\subsection{Evaluation from a Human Rights Perspective}

In the introduction (paragraph 1.4), the framework for this evaluation has already been given. In the mentioned Guzzardi-case, it was adopted that restrictions may be so severe as to amount to deprivation of liberty. In such a case, the safeguards of Article 5 ECHR come into play. Have the national legislators or judiciary in a single case ever tested restrictions through a supervision framework against the requirements of Article 5 ECHR? Or are restrictions measured against Article 2 Protocol 4 or other protected rights or liberties in the convention? And what other human rights documents - possibly soft law - are considered?

Although the studied jurisdictions have different ways of integrating the ECHR and subsequent case law in national law - described in the respective contributions - the ECHR and its subsequent case law are taken at heart - although in some countries more often by scholars than judiciary, let alone government. That this is not restricted to case law regarding their own country is demonstrated by the fact that almost all authors of the country contributions mention case law on Article 5 regarding the German situation (of preventive detention). As described, in this case law some elaborated safeguards relevant for preventive frameworks were formulated. Concerning the grounds for deprivation of freedom there has to be a 'sufficient causal connection between the conviction and the deprivation of liberty at issue' $(1, a)$. The ground of 'when it is reasonably considered necessary to prevent his committing an offence' $(1, \mathrm{c})$ only applies to pre-trial detention and not custody for preventive purposes without the person concerned being suspected of having already committed a criminal offence (Ostendorf v. Germany 2013).

It can be argued that as the causal relation is progressively weakened as the preventive detention continues, in order to keep perspective the execution should be distanced from a prison sentence (in special facilities compare the French decision on the internal regulations in Fresnes) and possibly a requirement of 'unsound mind' $(1$, e) should be in place (like in the Dutch TBS- order); compare the mentioned German makeshift when retroactive imposition of preventive detention was considered a heavier penalty incompatible with the legality requirements of Article $7 \mathrm{ECHR}$. That article also requires foreseeability, while Article 4 Protocol 7 states the right not to be punished twice.

A supervisory framework would only have to comply with these and other safeguards of Article 5 if its restrictions (in a single case) are to be considered a deprivation of liberty. The fact that the Guzzardi case is not mentioned by the legislator or judiciary may be consoling, in the sense that no restrictions of such severity are ever used, or worrying in the sense that people are not aware of the fact that restriction of liberty can turn into deprivation of liberty. In the Netherlands, concerning the legal requirement of one year of conditional release from TBS, if the dangerousness criterion is not met judiciary tends to impose the lightest possible restrictions as said to comply with Article 5. The idea that restriction can turn into deprivation, also through recall after breaching directions, has led some authors - of the contributions most strongly in the Dutch, French and Spanish perspective - to argue that supervisory frameworks as a precaution should comply with the safeguards of Article 5 as not to come into trouble in case restrictions are deemed as deprivation of liberty in a single case. That also seemed to be the idea of the Dutch legislator, as in the pre-legislative justification of the recently adopted Dutch framework an extensive human rights check was presented, including the standards of article 5 ECHR. Struijk and Mevis suggest that the twofold procedure of imposition at sentencing and the execution decision at the end of the sentence was directly related to the case law regarding the German nachträgliche Sicherungsvermahrung. However, they also see a downside of this procedure in terms of the required foreseeability (in Article 7) whether the order will be executed or not and with what restrictions and how the individuals behaviour in custody may influence the decision. Nonetheless, they consider the framework itself not to be in violation with the ECHR. The same is true for Meier's opinion on the German framework; he also considers the postcustody formulation of directions not to be a form of a second punishment.

The fact that both Article 5 and Article 3 - the prohibition of inhumane treatment, for example, in cases of life sentences - seem to require perspective seems to be in line with a requirement of detention aimed at rehabilitation as expressed in some constitutions as well as Article 10(3) ICCPR, even though the ECHR does not explicitly formulate it as a right.

In national case law, sometimes restrictions within a framework of supervision are considered an infringement on certain rights and liberties under the ECHR, not justified as provided by law, having a legitimate aim or necessary in a democratic society. In determining this, the interests of the offender have to be balanced against the rights and freedoms of potential victims (Colon v. the Netherlands 2012). In the Convention on the Protection of Children against Sexual Exploitation 
and Sexual Abuse (2007/2010), states have the obligation to provide preventive measures. This balance of interests is also provided for in German constitutional law.

In German case law, a direction to take up residence at a specific place prescribed by the competent division of the regional court was not covered by national law and was a violation of the released person's freedom of movement also under Article 2 (1), ECHR fourth protocol. In a pre-trial case, a direction to carry the equipment for electronic monitoring was considered a restriction of the offender's freedom of action under national law. In another case, the direction to make an effort to find employment immediately after release, in a sense of an obligation to accept any employment offered to him by an agency, was considered a violation of the released person's occupational freedom under national law and Article 15 Charter of Fundamental Rights of the European Union. In a final case, it was ruled that the direction not to publish right-wing ideas for a period of five years after release was a disproportionate interference with the offender's freedom of expression under national law and Article 10 (1) ECHR.

In national case law, the human rights perspective plays a role in relation to possible restrictions in a single case. However, as was described in paragraph 2.2 in relation to that or on top of that principles like certainty and proportionality may play an independent but similar role. This is to be understood through the fact that the ECHR itself provides merely a low threshold of minimum rights, while national courts can also be expected to develop equal, if not stronger, protections.

Of course, under the ECHR, infringements on certain rights and liberties may be justified if they are proportionate to a legitimate aim and pressing social need. In addition, all sorts of soft-law rules and recommendations have in common that they call for proportionality, defining this principle as proportionate to the seriousness of the committed offence, not the alleged offenders' risk and danger. For example the Council's Recommendation on Community Sanctions and Measures (2000/22, updated a 1992 version) merely states that a community sanction or measure ordinarily shall not be of indeterminate duration. But Struijk and Mevis consider a determined initial duration with possible prolongation as determinate enough. Other relevant recommendations are those on Probation Rules (2010/1) and conditional release (2003/22). With regard to electronic monitoring, a separate recommendation was recently adopted by the Council of Europe (2014/4),

to define a set of basic principles related to ethical issues and professional standards enabling national authorities to provide just, proportionate and effective use of different forms of electronic monitoring in the framework of the criminal justice process in full respect of the rights of the persons concerned.

Evaluation research showed that in terms of compliance generally, the rules are rather vague and lack of specific- ity resulting in all jurisdictions broadly adhering to the recommendation. Nevertheless, more detailed examination suggests that compliance is sometimes more technical than real and that more needs to be done in order for jurisdictions to comply more fully. ${ }^{44}$

\section{Conclusion}

The aim of this study was to find the legal constraints governing the supervision of sex offenders in the community because this group was presumably the group on which social control has its firmest grip. In all five studied jurisdictions in the past decades, changed attitudes towards sex offenders have expanded the legal possibilities of post-sentence supervision in a variety of new or adapted existing legal frameworks. Indeed, the provisions suggest that sex offenders are the group with the least protection in a sense that principles can be breached sooner. Even though the authors report a lack of empirical data, at least it can be concluded that this expansion (initially) leads to a more frequent use of supervision frameworks in practice, while in jurisdictions with several options to ensure supervision not all schemes are similarly popular. This general expansion suggests that in the process existing legal borders have been crossed or at least extended.

With regard to the legal constraints posed through sentencing theory, it may be concluded that in a twin-track system the more a safety measure, for example, for reasons of legal protection, is blurred with retrospective notions (of punishment) such as proportionality to the committed offence and the requirement of a committed offence (legality), the more theoretical borders seem to be acknowledged. The perspective of England and Wales shows that punishment can be blurred with preventive notions, or refuge can be taken to civil law, in a way that the original safeguards of punishment seem of lesser importance. It is suggested that if supervision is considered as less intrusive than detention, theoretical borders may be crossed sooner, such as a requirement of treatment or rehabilitation especially for indeterminate measures. However, like Stanley Cohen, some of the authors of the contributions suggest that this assessment of intrusiveness may deserve reconsidering.

With regard to constraints posed by the principle of proportionality, it is first important to note that many differences can be observed regarding the specific procedural safeguards that are in place. How serious should the required offence be, how high the threshold of dangerousness and how is the quality of the assessment of risk safeguarded, at what stage in the proceedings and by whom should supervision be imposed, when is indeterminacy justified and how frequent is periodic review possible, what possible restrictions may be imposed and what is the penalty on breaching them, what other procedural safeguards are in place and how differs the

44. Hucklesby et al., above n. 27. 
imposition in theory and in practice? Some difference may be explained through the principle itself by the rationale that more intrusive measures require more balancing safeguards. However, in that evaluation some fairly intrusive frameworks may be lacking counterbalance. This is even more true in practice than in theory, as the assessment of dangerousness itself seems to require counterbalance. Concerning concrete restrictions in case law, the principle of proportionality does seem to pose legal constraints on what are considered disproportionate restrictions. Especially a blanket prohibition on computer use or the Internet access may be considered disproportionate in several countries because it restricts the defendant in the use of means necessary for rehabilitation into modern society.

With regard to constraints posed by the principle of necessity or least intrusive means, the fact that supervision is generally considered less intrusive than alternative options of deprivation of liberty - even under mental health law - seems to justify supervision frameworks. However, as most frameworks of supervision serve as a safety net or last resort at the end of a long trajectory through the criminal justice system, it is essentially the ineffectiveness of that system that provides for the necessity of supervision. Resorting to supervision must not be used as a means to further erode treatment and rehabilitative efforts in the criminal justice system, meanwhile adding to its own necessity.

With regard to human rights constraints, many of the former discussions are echoed. The notion by the ECHR in the Guzzardi case that restrictions may be so severe as to amount to deprivation of liberty has led some authors to suggest that as a precaution also for frameworks of supervision, the safeguards of Article 5 should be in place. Rehabilitation efforts may be considered part of the requirements of Article 5 inter alia. In national case law sometimes directions of restriction of liberty are considered an infringement on certain rights or freedoms under the ECHR, including Article 2, fourth protocol, and Article 10. The requirement that infringements in order to be justified should be proportionate to the intended aim is in keeping with soft-law requirements and the finding that in national case law restrictions are also tested on these principles, while the ECHR solely provides minimum standards.

Having asked scholars to evaluate the supervision frameworks in place in their respective countries, it is of interest to know on which note they end their contributions. Two main concerns can be identified. First of all, most authors - including Meier whose wordings are most closely followed here - focus on the fact that from a theoretical point of view indeterminate supervision may be consistent with the principle of proportionality, but this requires assessing the degree of dangerousness which is in practice flawed by inevitability of systematic errors, making the protective function of the proportionality principle in theory remarkably more promising than in practice. The necessity and the adequacy of (indeterminate) supervision can in practice be easily misjudged. In order to address this problem, of impor- tance is not only evidence-based risk assessment, but also improving the validity of these prediction methods. Possibly also in light of the prohibition of 'arbitrary' impositions, Herzog-Evans argues that this should be countered also by a possibility of counter-expertise.

The second concern is the fact that the frameworks of supervision are prone to be in contradiction with the requirement of rehabilitation as they seem to favour control. According to Struijk and Mevis, this is related to the principle of least intrusive means or necessity, in the sense that the framework of supervision is mainly necessary as a result of a lack of treatment and rehabilitation efforts in other frameworks. Without rehabilitation efforts, supervision is deemed to be ineffective, and subsequently disproportionate. Herzog-Evans, and Martínez Garay and Correcher Mira point out that for rehabilitation more resources are needed. Padfield concludes that 'ironically, it may be the cost of controls and supervision in the community that effect more changes in the future ... Then it may not be a culture of "human rights" that protects sex offenders from disproportionate restriction and surveillance, but simply a financial calculation.'

It would indeed be a bitter conclusion that it is not predominantly law that controls the social control of sex offenders in the community. This study shows, however, that even though law does yield to the demands of social control in facilitating all kinds of measures directed at sex offenders, it still provides some legal constraints on the restrictions of rights and liberties under frameworks of supervision, mainly through safeguards derived from human rights or the principles of proportionality and necessity. However, as frontiers of supervision of sex offenders are continuously being pushed, and any small next step can easily be considered necessary and proportionate, those principles are rendered increasingly less meaningful. As these principles are also prone to various interpretations, their connection to human rights jurisprudence - like that on art. 5 ECHR - will remain relevant.

This study hopefully aids in initiating more debate and research on what remains an under-debated and underresearched issue. In fact, the debate itself is probably a vital part of the counterweight required in keeping the advancements of social control in check. 